\title{
DOS ESPECIES NUEVAS DE PERYMENIUM (COMPOSITAE- HELIANTHEAE) DEL CENTRO DE MÉXICO
}

\author{
Jerzy Rzedowski ${ }^{1}$ y Graciela Calderón de Rzedowski \\ Instituto de Ecología, A.C., Centro Regional del Bajío, Apdo. postal 386, \\ 61600 Pátzcuaro, Michoacán, México. \\ 1Autor para la correspondencia: jerzy.rzedowski@inecol.edu.mx
}

\section{RESUMEN}

Se describen como nuevos e ilustran Perymenium ibarrarum, del estado de México, así como P. moctezumae de Querétaro. La primera se asemeja y relaciona posiblemente con $P$. hintonii McVaugh. La segunda parece estar vinculada con P. tamaulipense B. L. Turner y con P. sotoarenasii Rzed. \& Calderón. Ambas se conocen únicamente de la colección tipo.

Palabras clave: Compositae, México, Perymenium, taxonomía.

\begin{abstract}
Perymenium ibarrarum and P. moctezumae are described as new and illustrated. The first one resembles and is possibly related to $P$. hintonii McVaugh; the second seems to be related to $P$. tamaulipense B. L. Turner and to $P$. sotoarenasii Rzed. \& Calderón. Both are only known from the type collections.
\end{abstract}

Key words: Compositae, México, Perymenium, taxonomy.

En 1978 Fay publicó la revisión del género Perymenium en México y Centroamérica, en la cual reconoció la existencia de 31 especies, de las cuales 5 resultaron ser nuevas. De entonces a esta fecha se han dado a conocer 13 novedades adicionales y siguen apareciendo otras más de distribución geográfica muy limitada.

A continuación se están describiendo otras dos, del estado de México y de Querétaro. 
Perymenium ibarrarum Rzed. \& Calderón sp.n. Fig.1.

Frutex volubilis vel scandens; folia anguste ovata vel lanceolata, 7-11 cm longa, 2-3.6 cm lata, acuminata, sparsim serrulata vel fere integra, supra strigulosa, infra hispidula; capitula in cymis umbelliformibus disposita, pedunculis singulis 2-7 mm longis; involucrum campanulatum, graduatum, bracteis $10-15$, infimis 6-7 mm longis scariosis tenuibus cum apice luteolo reflexo; flores radii 5-7, laminis oblongis 9-11 mm longis luteis; flores disci 10-12, corollis ca. $6 \mathrm{~mm}$ longis luteis; achenia radii discique (immatura) lineari-oblanceolata ca. $2 \mathrm{~mm}$ longa.

Arbusto voluble o trepador; ramillas estrigulosas con pelos de $0.2 \mathrm{~mm}$ o menos de largo, glabrescentes con la edad; hojas todas opuestas, peciolo de 3 a $7 \mathrm{~mm}$ de largo, lámina angostamente ovada a lanceolada, de 7 a $11 \mathrm{~cm}$ de largo, de 2 a $3.6 \mathrm{~cm}$ de ancho, acuminada en el ápice, cuneada a redondeada en la base, margen esparcidamente serrulado a casi entero, triplinervada, de textura membranácea, verde oscura y finamente estrigulosa en el haz, mucho más pálida, hispídula sobre las nervaduras y con numerosos puntos glandulosos en el envés; cabezuelas agrupadas en conjuntos cimosos umbeliformes terminales o ubicados en las axilas de las hojas superiores, pedúnculos de las umbelas hasta de $2.5 \mathrm{~cm}$ de largo, pedúnculos individuales de 2 a $7 \mathrm{~mm}$ de largo; involucro campanulado, sus brácteas 10 a 15, dispuestas en 2 a 3 series, las exteriores ovadas, de 3 a $4 \mathrm{~mm}$ de largo, gruesas y rígidas, densamente estrigulosas por fuera, las interiores oblongas, de 6 a $7 \mathrm{~mm}$ de largo, escariosas, delgadas, con el ápice amarillento y reflejo, pubérulas a casi glabras por fuera, receptáculo plano, páleas oblongas, de ca. $6 \mathrm{~mm}$ de largo, puntiagudas, glabras o casi glabras; flores liguladas 5 a 7, fértiles, sus láminas oblongas, de 9 a 11 $\mathrm{mm}$ de largo, amarillas, hispídulas sobre las nervaduras por fuera; flores del disco 10 a 12, sus corolas tubulosas, de ca. $6 \mathrm{~mm}$ de largo, de los cuales $2 \mathrm{~mm}$ corresponden al tubo y $1 \mathrm{~mm}$ a los lóbulos, amarillas, hispídulas en los lóbulos por fuera, anteras de ca. $3 \mathrm{~mm}$ de largo, cafés, ramas del estilo lineares, ligeramente ensanchadas, puntiagudas e hispídulas en el ápice; aquenios (inmaduros) linear-oblanceolados, de ca. $2 \mathrm{~mm}$ de largo, los del radio triquetros, los de las flores del disco comprimidos, de color café, hispídulos en las costillas, vilano de ca. 20 aristas delgadas de largo desigual, las más largas de $3 \mathrm{~mm}$ de longitud, las más cortas de $1.5 \mathrm{~mm}$.

Tipo: México, Estado de México, camino a Cerro Pelón por San Juan Xoconusco, municipio de Donato Guerra. Reserva de la Biosfera Mariposa Monarca. $19^{\circ} 21^{\prime} 02^{\prime \prime} \mathrm{N}$ y $100^{\circ} 14^{\prime} 40^{\prime \prime}$ O. Altitud. $2770 \mathrm{~m}$. Vegetación. Bosque con elementos 
Rzedowski y Calderón de Rzedowski: Dos especies nuevas de Perymenium (Compositae) del centro de México

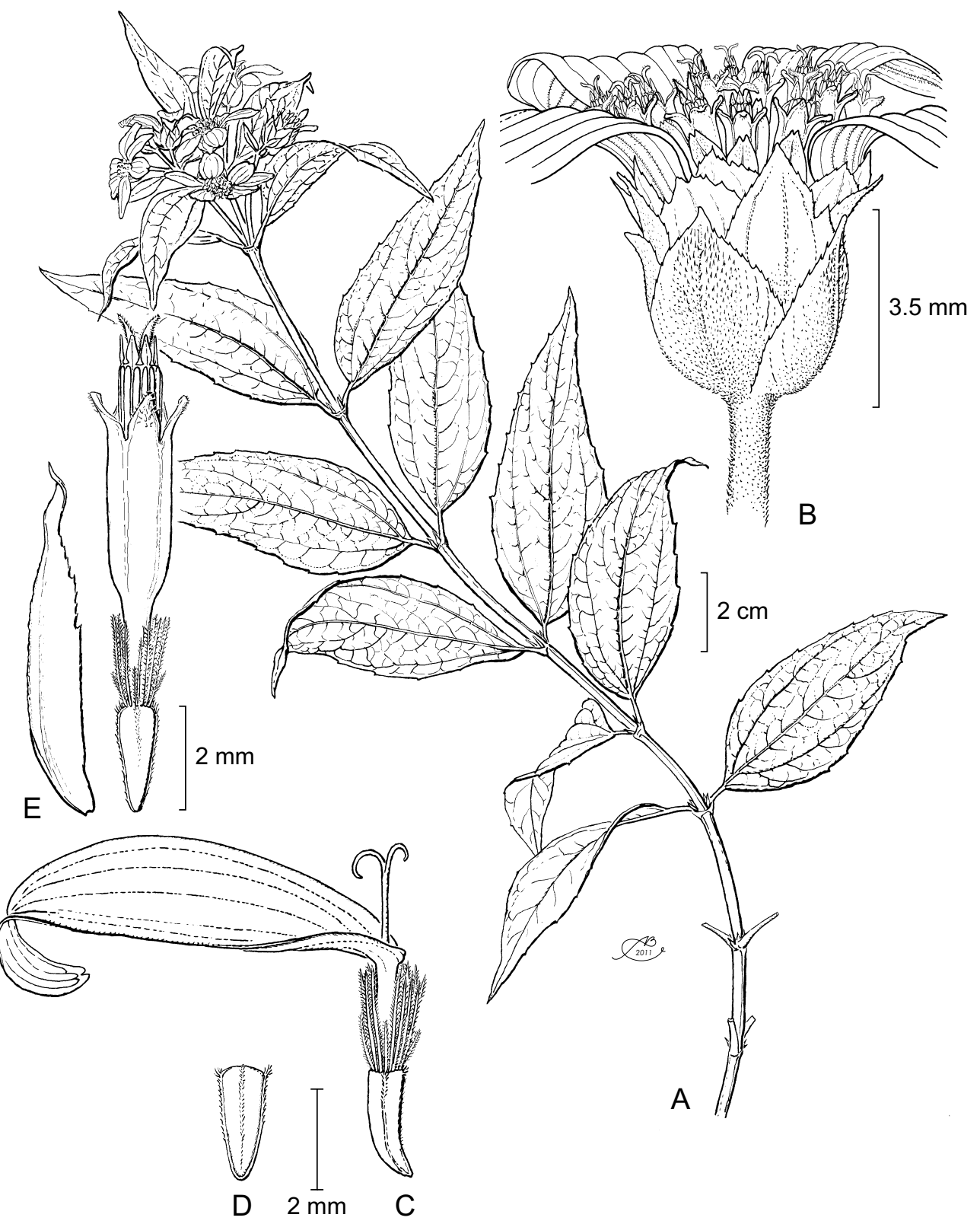

Fig. 1. Perymenium ibarrarum Rzed. \& Calderón. A. rama con hojas y cabezuelas; B. involucro; C. flor ligulada en vista lateral; D. aquenio de la flor ligulada en vista frontal; E. flor del disco y su pálea. Ilustrado por Alfonso Barbosa. 
mesófilos (Alnus, Cupressus, Cornus y Styrax). 21.XII.2006. G. Ibarra Manriquez (5160) y Guadalupe Cornejo Tenorio (IEB), isotipos por distribuirse.

La especie sólo se conoce de esta colecta y probablemente representa un estrecho endemismo.

P. ibarrarum muestra cierta semejanza con $P$. hintonii McVaugh, conocido del oeste de Michoacán y de la porción meridional del estado de México, pero difiere en su hábito voluble, en sus hojas proporcionalmente más estrechas y no ampollosas en el envés, en sus inflorescencias mucho más compactas (pedúnculos individuales hasta de $7 \mathrm{~mm}$ de largo, vs. $1 \mathrm{a} 4 \mathrm{~cm}$ ), en sus cabezuelas más pequeñas y con menos flores (radio con 5 a 7, vs. 7 a 9; disco con 10 a 12, vs. 16 a 20), en sus aquenios más chicos (ca. $2 \mathrm{~mm}$, vs. 3.3 a $4.7 \mathrm{~mm}$ de largo), así como en sus afinidades ecológicas (alt. 2770 $\mathrm{m}$, vegetación de bosque de encino y pino con elementos mesófilos, vs. alt. 750 a 950 $\mathrm{m}$, vegetación de bosque tropical caducifolio).

En algunos aspectos $P$. ibarrarum es similar también a $P$. berlandieri DC., planta conocida del Valle de México, así como de sitios aledaños de Hidalgo, Morelos y Puebla, pero se separa de esa especie en sus brácteas involucrales interiores de aspecto petaloide.

El nombre de la especie se dedica a Guillermo Ibarra Manríquez y a su esposa Guadalupe Cornejo de Ibarra, botánicos mexicanos, colectores de una muestra de esta interesante novedad. Entre otras contribuciones, los Ibarra han dedicado un particular esfuerzo al conocimiento detallado de la flora de la Reserva de la Biosfera Mariposa Monarca, ubicada en los límites de Michoacán y del estado de México.

Perymenium moctezumae Rzed. \& Calderón sp.n. Fig.1.

Frutex ca. $1.5 \mathrm{~m}$ altus; folia lanceolata vel anguste ovata $3.5-6.5 \mathrm{~cm}$ longa, 1.2-3 cm lata, acuminata, serrata vel serrulata, supra minute scabriuscula, infra dense hispidula; capitula in cymis paucifloribus terminalibus disposita, pedunculis usque $8 \mathrm{~cm}$ longis; involucrum campanulatum graduatum bracteis 12-15 apice purpureis; flores radii 5-8, laminis oblongis vel ellipticis 5-6 mm longis luteo-aurantiacis; flores disci 20-30, corollis 4-5 longis luteis; achenia radiii trapezoidea valde compressa ca. $2 \mathrm{~mm}$ longa fere aequilata, achenia disci anguste oblonga ca. $2 \mathrm{~mm}$ longa, minus quam $1 \mathrm{~mm}$ lata.

Arbusto de ca. $1.5 \mathrm{~m}$ de alto; ramillas café-rojizas, cubiertas con pubescencia escabriúscula con pelos de tamaño muy variable, de 0.0 .5 a $0.5 \mathrm{~mm}$ de largo; 
Rzedowski y Calderón de Rzedowski: Dos especies nuevas de Perymenium (Compositae) del centro de México

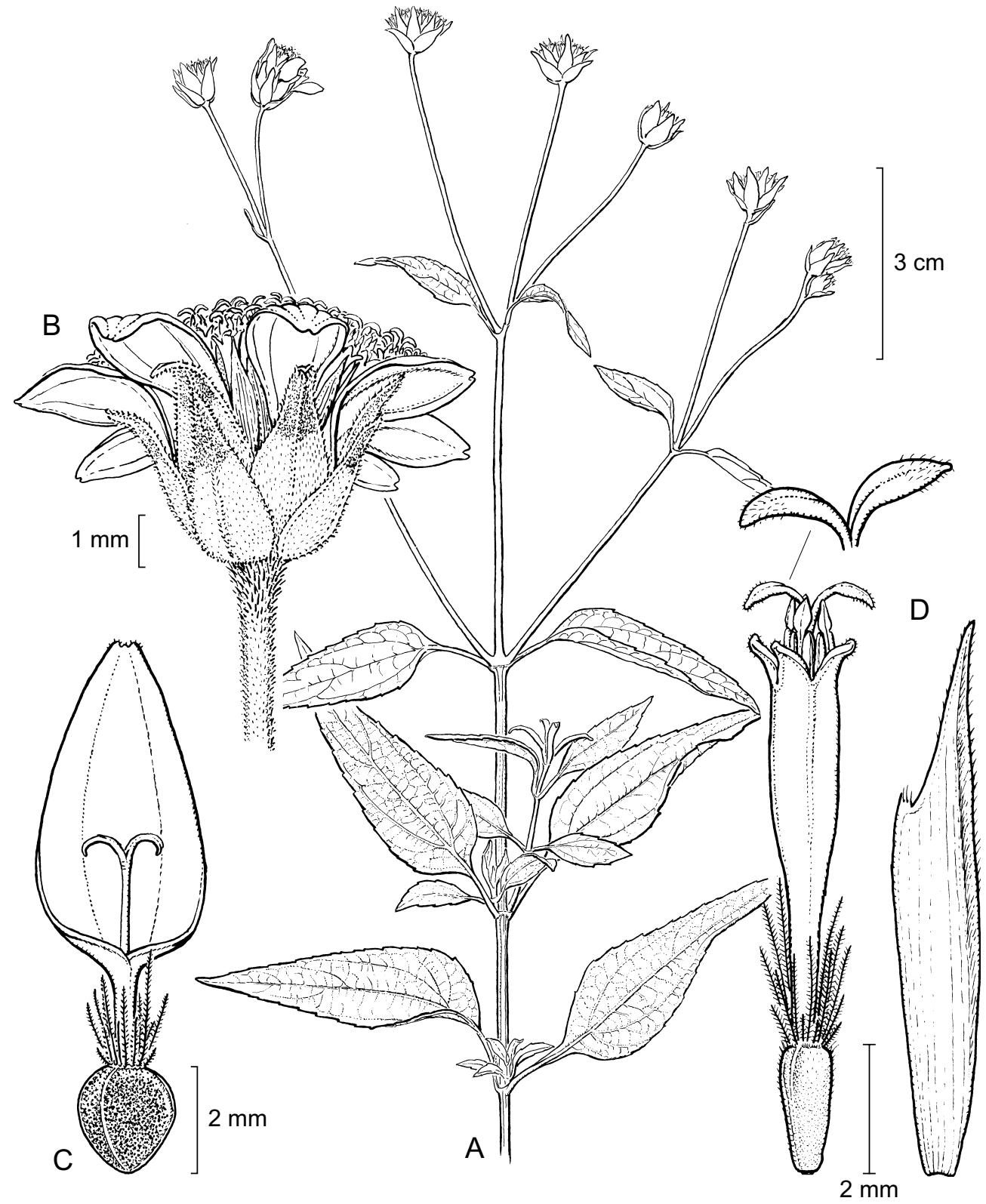

Fig. 2. Perymenium moctezumae Rzed. \& Calderón. A. rama con hojas y cabezuelas; B. cabezuela; C. flor ligulada; D. flor del disco con su pálea y detalle de las ramas del estilo. Ilustrado por Alfonso Barbosa. 
hojas opuestas, peciolo de 6 a $12 \mathrm{~mm}$ de largo, lámina lanceolada a estrechamente ovada, de 3.5 a $6.5 \mathrm{~cm}$ de largo, de 1.2 a $3 \mathrm{~cm}$ de ancho, acuminada en el ápice, redondeada en la base, margen serrado a serrulado, de textura cartácea, verde oscura y finamente escabriúscula en el haz, mucho más pálida y densamente hispídula en el envés; cabezuelas agrupadas por varias en conjuntos cimosos terminales, sobre pedúnculos hasta de $8 \mathrm{~cm}$ de largo; involucro campanulado, sus brácteas 12 a 15, dispuestas en 2 a 3 series, las exteriores ( 1 o 2 ) ovadas, de 3 a $4 \mathrm{~mm}$ de largo, las interiores lanceoladas, de 5 a 6(7) $\mathrm{mm}$ de largo, todas puntiagudas y moradas en el ápice, densamente hispídulas por fuera con pelos aplicados de ca. $0.5 \mathrm{~mm}$ de largo, receptáculo convexo, páleas oblongas, de 5 a $7 \mathrm{~mm}$ de largo, puntiagudas y moradas en el ápice, hispídulas a lo largo de la quilla y en el ápice por fuera; flores liguladas 5 a 8, fértiles, sus láminas oblongas a elípticas, de 5 a $6 \mathrm{~mm}$ de largo, amarillo-anaranjadas, hispídulas hacia el ápice por fuera; flores del disco 20 a 30, sus corolas tubulosas, de 4 a $5 \mathrm{~mm}$ de largo, amarillas y a menudo con tintes morados en la madurez, hispídulas en los lóbulos por fuera, anteras de ca. $3 \mathrm{~mm}$ de largo, negruzcas, aquenios de las flores liguladas trapezoidales, fuertemente comprimidos, de ca. $2 \mathrm{~mm}$ de largo y casi otro tanto de ancho, negruzcos, hispídulos en la mitad distal, los de las flores del disco angostamente oblongos, del mismo largo pero de menos de $1 \mathrm{~mm}$ de ancho, vilano de 15 a 20 aristas de longitudes diversas, las más cortas de $0.3 \mathrm{~mm}$ de largo, las más largas de $2.5 \mathrm{~mm}$, todas fácilmente caedizas.

Tipo: México, Querétaro, aprox. $3.5 \mathrm{~km}$ al $\mathrm{W}$ de Las Moras por la carretera a San Joaquín, municipio de Cadereyta, 2052'42" N, 99²7'52" W, alt. 1260 m, ladera de rocas lutitas y calizas con matorral submontano, 18.IX.2010, S. Zamudio, R. Galván y C. E. Martínez 14938 (IEB), isotipos por distribuirse.

La especie sólo se conoce de esta colecta y probablemente representa un estrecho endemismo del cañón del río Moctezuma, aunque es de esperar también su presencia en las laderas opuestas de la misma barranca, pertenecientes al estado de Hidalgo.

P. moctezumae parece estar relacionado con P. tamaulipense B. L. Turner, planta conocida de la Sierra Madre Oriental de Tamaulipas, pero se distingue por su hábito leñoso (vs. herbáceo), por sus hojas más pequeñas ( 3.5 a $6.5 \mathrm{~cm}$ x 1.2 a 3 $\mathrm{cm}$, vs. 6 a $10 \mathrm{~cm}$ x 3 a $5 \mathrm{~cm}$ ), por sus brácteas involucrales puntiagudas (vs. obtusas en el ápice), por sus flores liguladas menos numerosas y más cortas (5 a 8, vs. 10 a 11; láminas de 5 a $6 \mathrm{~mm}$, vs. 7 a $10 \mathrm{~mm}$ de largo), por sus flores del disco con los 
lóbulos corolinos hispídulos, (vs. glabras), así como por sus aristas del vilano más numerosas (15 a 20 , vs. 8 a 10$)$.

La especie nueva también señala vínculos con $P$. sotoarenasii Rzed. \& Calderón, conocido de porciones vecinas del estado de Querétaro, pero a su vez difiere en sus hojas más grandes ( 3.5 a $6.5 \mathrm{~cm}$ x 1.2 a $3 \mathrm{~cm}$, vs. 0.8 a $3 \mathrm{~cm}$ x 0.5 a $1.8 \mathrm{~cm}$ ) y con indumento diferente (hispídulas, vs. viloso-tomentosas en el envés), en sus aquenios de radio trapezoidales y de ca. $2 \mathrm{~mm}$ de ancho (vs. triquetros y de menos de $1 \mathrm{~mm}$ de ancho), así como por las aristas del vilano más numerosas (15 a 20, vs. ca. 10).

\section{LITERATURA CITADA}

Fay, J. J. 1978. Revision of Perymenium (Astereae-Heliantheae) in Mexico and Central America. Allertonia 1: 235-296. 